\title{
Induction of nitric oxide production in mouse macrophages by Shiga toxin
}

\author{
Y. YUHAS, E. KAMINSKY, M. MOR* and SHAI ASHKENAZI*+ \\ Felsenstein Medical Research Center and*Schneider Childrens Medical Center, Beilinson Medical Campus, \\ Petah Tikva and †Sackler Faculty of Medicine, Tel Aviv University, Tel Aviv, Israel
}

\begin{abstract}
Host mediators play an important role in the pathogenesis of shigellosis and Shiga toxin toxicity. Nitric oxide (NO) production in mouse peritoneal macrophages and in the macrophage $\mathbf{J} 744$ cell line in response to purified Shiga toxin and lipopolysaccharide (LPS) from Shigella flexneri were studied. Shiga toxin induced NO production in a dosedependent manner up to $800 \mathrm{ng} / \mathrm{ml}$. Detectable levels of NO were present as early as $4 \mathrm{~h}$ after induction and continued to increase during $72 \mathrm{~h}$; Shiga toxin induced greater NO production with time than did LPS. Pre-treatment of Shiga toxin $(400 \mathrm{ng} / \mathrm{mI})$ or LPS $(10 \mathrm{ng} / \mathrm{ml})$ with polymyxin B, which inactivates LPS, reduced their ability to induce NO by $28 \%$ and $96 \%$, respectively. Induction in the presence of anti-TNF $\alpha$ antibodies did not reduce the amount of NO in the supernate. These studies showed that Shiga toxin induces NO production in murine macrophages.
\end{abstract}

\section{Introduction}

Shiga toxin is the main toxic product of Shigella dysenteriae type 1 , which is the aetiological agent of dysenteric outbreaks in developing countries [1]. Occasionally the diarrhoeal disease is accompanied by extra-intestinal complications such as haemolytic uraemic syndrome (HUS) and neurological disturbances, mainly encephalopathy and seizures [2-4]. Other Shigella spp. may also produce Shiga toxin or similar toxins. In addition, certain Escherichia coli serotypes that cause diarrhoea and haemorrhagic colitis produce closely related toxins named Shiga-like toxin I (SLT I) and Shiga-like toxin II (SLT II) $[4,5]$. SLT I differs from Shiga toxin only by a single amino acid, whereas SLT II shares with Shiga toxin c. 58\% homology of amino acids. SLTs are identical to Shiga toxin with regard to structure, cell binding receptor and biological activities. All inhibit protein synthesis through $\mathrm{N}$-glycosidase activity on rRNA and exert cytotoxicity on certain cell types, including endothelial cells $[5,6]$.

The contribution of Shiga toxin and SLTs to the pathogenesis of intestinal disease has been confirmed in several animal models that demonstrated more severe disease with Shiga toxin-producing strains
$[7,8]$. Numerous epidemiological studies established a correlation between the production of both toxins and the development of haemorrhagic colitis and HUS. The role of Shiga toxin in neurological manifestations is less evident. Shiga toxin has been considered a neurotoxin because of its ability to cause paralysis and death in laboratory animals [9-11]. Recent studies in a new animal model of neurotoxicity have shown that Shiga toxin and LPS act in concert to enhance pentylenetetrazol (PTZ)-induced seizures in mice [12].

Despite conspicuous evidence for the involvement of Shiga toxin and SLTs in the pathogenic processes, little is known about the mechanism by which they exert their damage. Accumulating data indicate that host mediators may play an important role in Shiga toxin toxicity. Based on histological studies it has been suggested that direct cytotoxic damage to endothelial and colonic cells enables the influx of macrophages and neutrophils to the site of the injured tissue. The local release of inflammatory factors that follows stimulates the inflammatory reaction and intensifies the tissue damage. Consistent with this assumption is the observed correlation between increased production of tumour necrosis factor $\alpha$ (TNF- $\alpha$ ), interleukin-6 (IL-6) and interferon- $\gamma$ (IFN- $\gamma$ ) and the severity of colonic damage [13]. Moreover, recently it was reported that SLT I and II themselves can induce production of TNF- $\alpha$, IL- $1 \beta$ and IL- 6 $[14,15,16]$, and that the lethality of SLT II in mice was macrophage dependent [15]. 
To further investigate the involvement of host mediators in Shiga toxin-mediated toxicity, the aim of this study was to examine whether Shiga toxin can induce another host mediator, the nitric oxide (NO) molecule. In the last few years, NO has been recognised as a major messenger in diverse pathophysiological functions, such as vasodilation, increased vascular permeability, bactericidal and cell cytotoxic activities and neurotransmission $[17,18]$. As a neurotransmitter, NO acts both in the central nervous system (CNS) and in the peripheral non-adrenergic non-cholinergic nervous system. NO is induced by LPS and various combinations of cytokines in various cell types including macrophages, neutrophils and endothelial cells. Its excessive release during infections has been linked to the severe pathological manifestations of sepsis and inflammation. Recently it has been proposed that NO may also be involved in the neurological disturbances in infectious diseases such as cerebral malaria and meningitis [19-21].

\section{Materials and methods}

\section{Reagents}

LPS from $S$. flexneri serotype 1a was obtained from Sigma. LPS was stored at $-20^{\circ} \mathrm{C}$ and thawed only once. For making serial dilutions, each solution was vortex mixed for $20-30 \mathrm{~s}$ before transfer to the next tube. Polymyxin B (Sigma) was freshly prepared in medium before use.

\section{Quantification of LPS}

The Limulus amoebocyte lysate assay (Cape Cod Associates, Woods Hole, MA, USA) sensitive to endotoxin $0.065 \mathrm{U} / \mathrm{ml}$ was used according to the manufacturer's specifications.

\section{Purification of Shiga toxin}

Shiga toxin was purified from a sonicate of $S$. dysenteriae 1 strain $60 \mathrm{R}$ by Affi-Gel blue (BioRad Laboratories, Richmond, CA, USA), affinity column chromatography, chromatofocusing and hydroxylapatite column chromatography as described previously [22] with confirmation of purity by silver staining. The Shiga toxin contained $12 \mathrm{ng}$ of $\mathrm{LPS} / \mu \mathrm{g}$ protein.

\section{Cell cultures}

Peritoneal macrophages were prepared from ICR male mice, aged 4-6 weeks as described previously [23]. Mice were first given sodium periodate $(1 \mathrm{ml}$ of $5 \mathrm{mM}$ solution) by intraperitoneal injection; 3 days after injection, peritoneal exudate cells were collected by peritoneal lavage with $10 \mathrm{ml}$ of phosphate-buffered saline (PBS). Cells were seeded in 96-well microtitration plates at a concentration of $10^{5}$ cells/well in RPMI with heat inactivated fetal calf serum (FCS) $10 \%$. Cells were incubated for $2 \mathrm{~h}$ at $37^{\circ} \mathrm{C}$ in humidified air $+\mathrm{CO}_{2}$ $5 \%$, then washed three times with RPMI to remove non-adherent cells and incubated overnight in RPMI with FCS 5\%. The following day, medium was replaced with fresh medium and the inducers were added as indicated in the text. In some experiments the inducers were pre-incubated with polymyxin B $5 \mu \mathrm{g} / \mathrm{ml}$ for $6 \mathrm{~h}$ at room temperature.

\section{$J 744$ cells}

A BALB/c-derived macrophage-like cell line (J744) was grown in Dulbecco's modified minimum essential medium (DMEM) containing heat inactivated FCS $10 \%$. All media were supplemented with penicillin $100 \mathrm{U} / \mathrm{ml}$, streptomycin $100 \mu \mathrm{g} / \mathrm{ml}$ and amphotericin B $250 \mathrm{ng} / \mathrm{ml}$ (medium and supplements were purchased from Biological Industries, Beit Haemek, Israel). The media used did not contain detectable levels of LPS.

\section{Determination of $N O$ production}

Nitrite $\left(\mathrm{NO}_{2}^{-}\right)$concentration was measured as an indicator of NO production by the spectrophotometry method based on the Griess reaction as described previously [23]. Samples of $50-100 \mu \mathrm{l}$ of culture supernates were added to equal volumes of Griess reagent (sulphanilamide $1 \%$, naphtyl-ethylenediamine $0.1 \%$ in $\mathrm{H}_{3} \mathrm{PO}_{4} 2 \%$ ). The absorbance at $540 \mathrm{~nm}$ was measured after $10 \mathrm{~min}$ at room temperature by an enzyme-linked immunosorbent assay (ELISA) plate reader. $\mathrm{NO}_{2}^{-}$concentrations were calculated from a standard curve of $\mathrm{NaNO}_{2}$ included in each test.

\section{TNF determination}

TNF $\alpha$ levels were determined by the cytotoxic activity assay on mouse L929 cells [24]. Each assay included a standard curve of recombinant human TNF- $\alpha$ (specific activity $2.5 \times 10^{7} \mathrm{U} / \mathrm{mg}$ protein), kindly provided by Dr T. Amarant (Reprogen Ltd, Rehovot, Israel).

\section{Statistical analysis}

All experiments were performed at least three times. Data are presented as mean and standard deviation (SD). Significance was determined by analysis of variance (for three groups or more) or Student's $t$ test (for two groups).

\section{Results}

\section{Production of NO in J744 cells}

Shiga toxin induced NO both in murine peritoneal macrophages and in the murine macrophage cell line (Figs. 1 and 2). The induction was dose dependent and the differences in NO production between the Shiga toxin- or LPS-treated groups and the controls were statistically significant $(p<0.001)$. In J744 cells the 


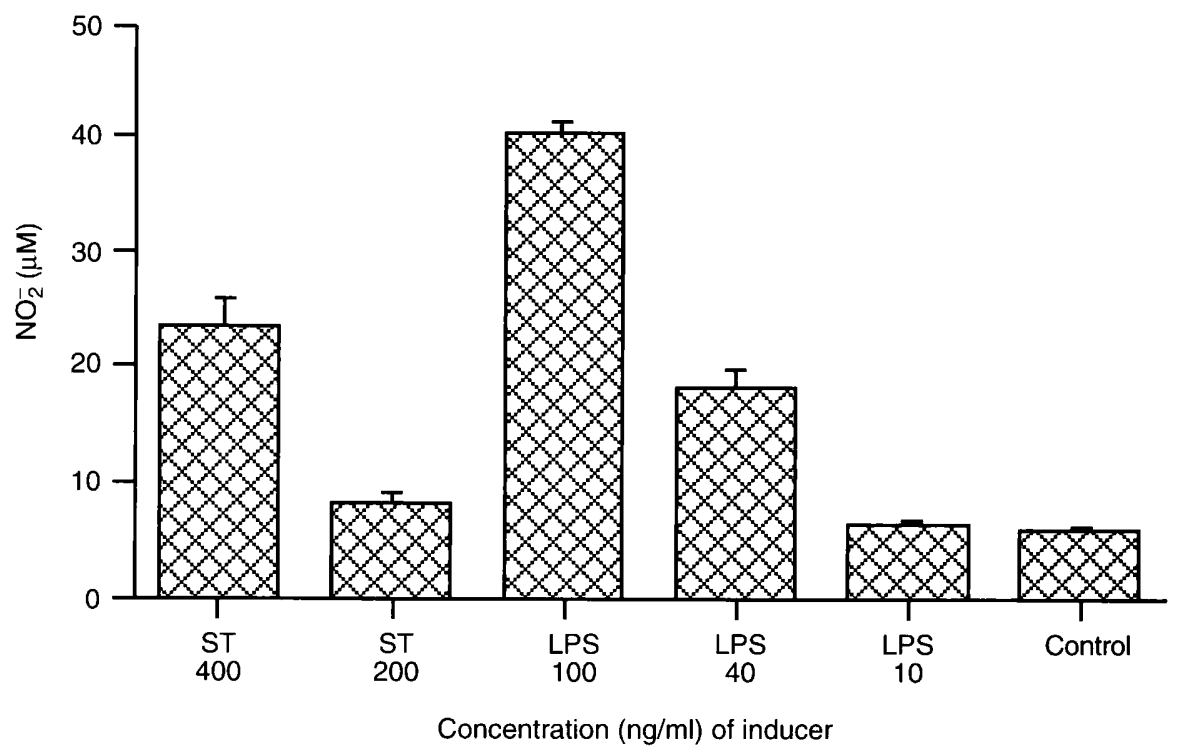

Fig. 1. Induction of NO by Shiga toxin (ST) and LPS in J744 cells. J744 cells $\left(10^{5}\right.$ cells $\left./ 100 \mu 1\right)$ were incubated with Shiga toxin or LPS from $S$. flexneri at the concentrations indicated or with medium alone (control) for $48 \mathrm{~h}$ at $37^{\circ} \mathrm{C}$. The supernates were collected and assayed for $\mathrm{NO}_{2}^{-}$. The data shown are the mean of triplicate readings of one of three similar experiments and the bars represent SD.

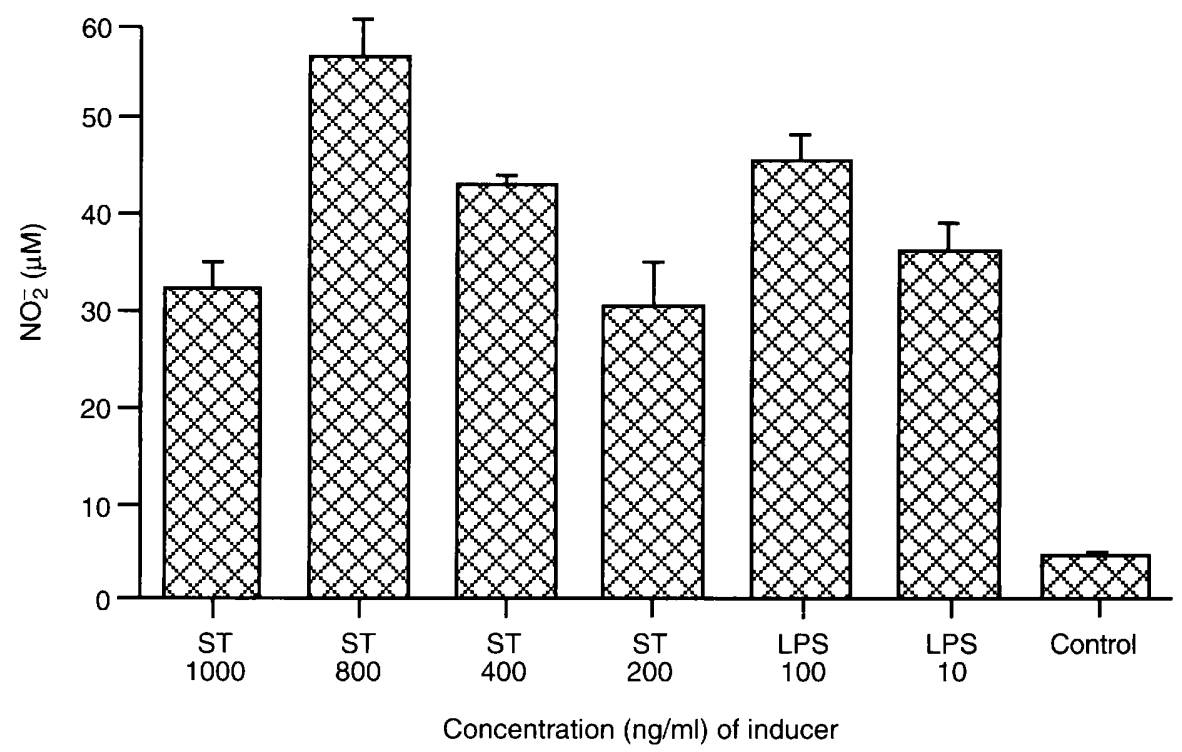

Fig. 2. Induction of NO by Shiga toxin (ST) and LPS in mouse peritoneal macrophages. Macrophages $\left(10^{5}\right.$ cells $\left./ 100 \mu 1\right)$ were incubated with Shiga toxin or LPS from $S$. flexneri at the concentrations indicated or with medium alone (control) for $48 \mathrm{~h}$ at $37^{\circ} \mathrm{C}$. The data shown are the mean of triplicate readings of one of at least five similar experiments and the bars represent $\mathrm{SD}$.

amount of NO produced in response to Shiga toxin $400 \mathrm{ng} / \mathrm{ml}$ was similar to the amount induced by LPS derived from $S$. flexneri $(50-100 \mathrm{ng} / \mathrm{ml})$ (Fig. 1). The J744 cells were relatively insensitive to LPS. Thus, LPS $10 \mathrm{ng} / \mathrm{ml}$ - which induced a high level of NO in peritoneal macrophages - did not elicit NO production in J744 cells. Moreover, on some occasions the J744 cells became resistant to LPS, not responding to $100 \mathrm{ng} / \mathrm{ml}$ or even $10 \mu \mathrm{g} / \mathrm{ml}$, yet still produced small quantities of NO in response to Shiga toxin (data not shown). As the amount of LPS in the Shiga toxin preparation was $12 \mathrm{ng} / \mu \mathrm{g}$ of protein, the induction of NO in these cells can be attributed to Shiga toxin itself.

\section{Production of NO in peritoneal macrophages}

In peritoneal macrophages, Shiga toxin induced NO in a dose-dependent manner up to $800 \mathrm{ng} / \mathrm{ml}$ (Fig. 2). Higher concentrations $(1 \mu \mathrm{g} / \mathrm{ml})$ were less effective, probably due to the inhibitory effect of Shiga toxin on protein synthesis. However, peritoneal macrophages responded to low concentrations of LPS $(0.5 \mathrm{ng} / \mathrm{ml})$. To overcome this difficulty, the Shiga toxin was treated 
with polymyxin $\mathrm{B}$, an antibiotic which inactivates LPS by binding to lipid $A$. Incubation of Shiga toxin $400 \mathrm{ng} / \mathrm{ml}$ with polymyxin B $5 \mu \mathrm{g} / \mathrm{ml}$ for $6 \mathrm{~h}$ at room temperature reduced its ability to induce NO by $15-$ $50 \%$ (mean $28 \%$ ). In contrast, treatment of LPS $10 \mathrm{ng} /$ $\mathrm{ml}$ with the same concentration of polymyxin B reduced its ability to induce NO by $94-100 \%$ (mean $96 \%$ ) and lowered the activity of LPS $100 \mathrm{ng} / \mathrm{ml}$ by $72-95 \%$ (mean $86 \%$ ). The differences between the inhibitory effect of polymyxin B on NO production by Shiga toxin and LPS were statistically significant $(p<0.001)$. The dose response of Shiga toxin and LPS with and without polymyxin $B$ treatment is shown in Fig. 3. The reduction of NO induction by Shiga toxin at the different concentrations tested
$(50-400 \mathrm{ng} / \mathrm{ml})$ was by $1-6.5 \mu \mathrm{M}$. These amounts of NO corresponded to the amounts induced by LPS 1$5 \mathrm{ng} / \mathrm{ml}$ which was present in the various concentrations of Shiga toxin.

\section{Kinetics of NO induction by Shiga toxin in J744 cells}

To determine the kinetics of NO induction by Shiga toxin in $\mathrm{J} 744$ cells, supernates were assayed for nitrite at $4,8,24,48$ and $72 \mathrm{~h}$ after the stimulation. Fig. 4 shows the kinetics of NO and TNF production in response to Shiga toxin and LPS in J744 cells. Detectable levels of NO were already present $4 \mathrm{~h}$ after stimulation and continued to accumulate in the culture

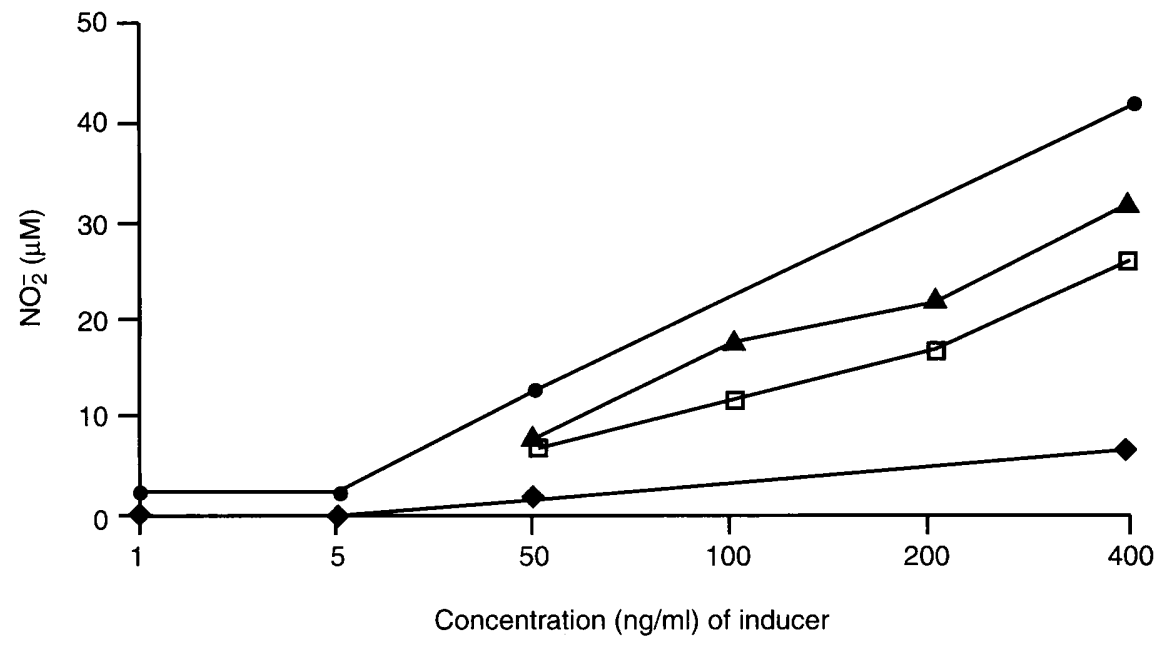

Fig. 3. Comparative dose response of induction of NO by Shiga toxin (ST) or LPS before and after pre-treatment with polymyxin B. Shiga toxin and LPS were incubated with either polymyxin B or medium for $6 \mathrm{~h}$ at room temperature before application of peritoneal macrophages $\left(10^{5}\right.$ cells/100 $\left.\mu \mathrm{l}\right)$. Supernates were harvested and assayed for $\mathrm{NO}_{2}^{-}$ formation $48 \mathrm{~h}$ after stimulation. Each point represents an average of triplicate reading of one of two similar experiments; $\boldsymbol{\bullet}$, LPS + medium; $\boldsymbol{\Delta}$, Shiga toxin + medium; $\square$, Shiga toxin + polymyxin B; $\bullet$, LPS + polymyxin B.

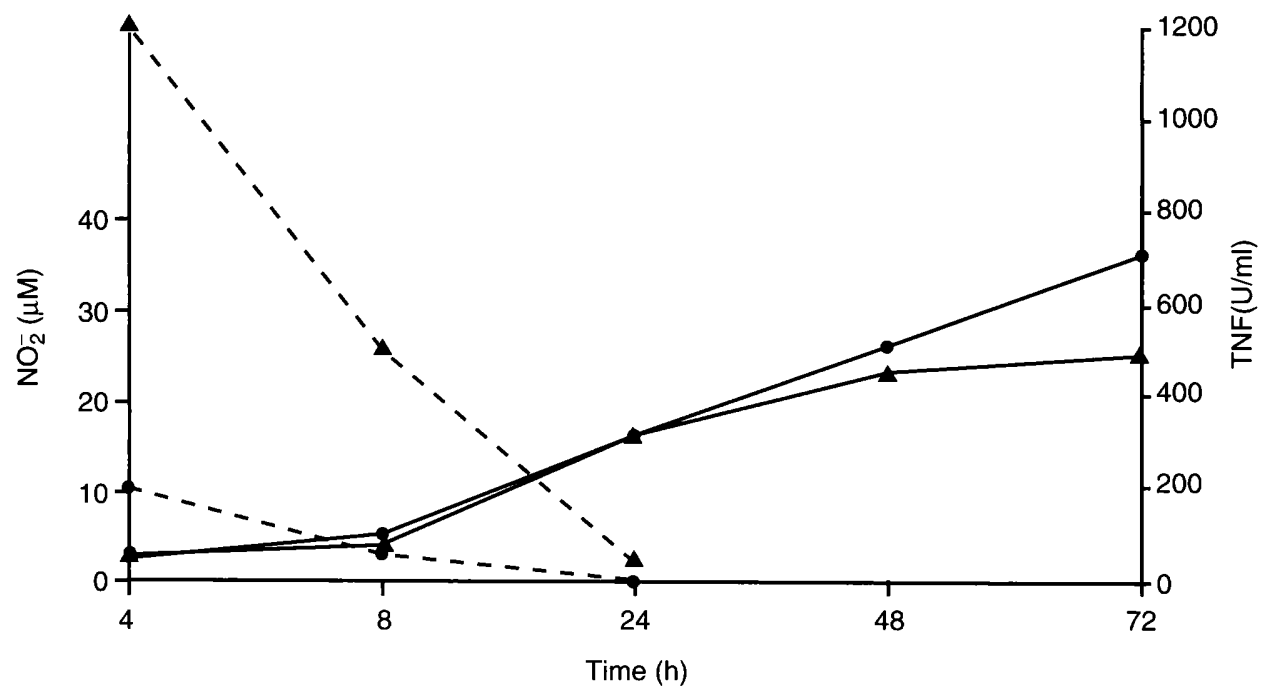

Fig. 4. Kinetics of NO (-) and TNF (- - -) induction by Shiga toxin (ST) (-) or LPS ( $\mathbf{\Delta})$ in J744 cells. J744 cells $\left(10^{5}\right.$ cells $\left./ 100 \mu \mathrm{l}\right)$ were stimulated with Shiga toxin $400 \mathrm{ng} / \mathrm{ml}$ or LPS $100 \mathrm{ng} / \mathrm{ml}$. At the time points indicated, supernates were collected and assayed for $\mathrm{NO}_{2}^{-}$and TNF concentration. Each point represents an average of triplicate readings of one of three similar experiments. 
during the next $72 \mathrm{~h}$. As previously reported, Shiga toxin also induced TNF. The production of TNF was quicker and shorter than that of $\mathrm{NO}$, as most of the TNF was produced during the first $8 \mathrm{~h}$ and declined afterwards. The production of NO was not mediated through TNF, as stimulation with Shiga toxin in the presence of anti-mouse TNF $\alpha$, which completely neutralised the TNF present in the supernates, did not change the amount of NO induced (data not shown).

\section{Discussion}

The results presented provide evidence that Shiga toxin stimulates the production of NO in murine macrophages. As previously reported, Shiga toxin also induces TNF. In this property of inducing concomitantly cytokines and NO, Shiga toxin resembles other inducers such as LPS, staphylococcal glycocalyx and Borrelia burgdorferi $[25,26]$. NO production in murine macrophages is unlikely to be caused by LPS contamination, as a higher concentration of LPS than that present in the preparation used was completely inactive in $\mathbf{J} 744$ cells. In peritoneal macrophages which respond to low concentrations of LPS, pre-treatment of Shiga toxin with polymyxin B, which inactivates LPS, only partially reduced its ability to induce NO, while almost completely abolishing LPS activity ( $28 \%$ versus $96 \%$, respectively, $\mathrm{p}<0.001$ ). Also, NO production was not stimulated through TNF since its production occurred in the presence of anti-mouse TNF $\alpha$, which neutralised the TNF present in the supernate. This result is in agreement with those of Ding et al. [23], who found that TNF $\alpha$ did not induce NO in murine macrophages. Nevertheless, an interaction between Shiga toxin and LPS which results in higher NO production cannot be excluded. This may be important in vivo.

The kinetics of NO production in $\mathbf{J} 744$ cells in response to Shiga toxin and LPS are similar. However, the increase of NO production with time after exposure is greater in response to Shiga toxin than to LPS (Fig. 4). This suggests that the regulation of NO production in response to Shiga toxin and LPS may be different. Dose-response studies in peritoneal macrophages showed that NO induction was maximal at a Shiga toxin concentration of $800 \mathrm{ng} / \mathrm{ml}$. Higher concentrations of Shiga toxin were less effective. This may be related to the inhibitory effect of Shiga toxin on protein synthesis. Alternatively, high concentrations of Shiga toxin may exert cytotoxic activity on macrophages.

The exact contribution of NO induced by Shiga toxin to the pathological processes is yet unknown. NO, TNF $\alpha$, IL- $1 \beta$ and IL- 6 are all induced more efficiently by LPS than by Shiga toxin $[14,15]$. Interestingly, Barrett et al. [27] found that LPS either increased or decreased the lethality of SLT II in mice and rabbits depending on the time of its application. Therefore it is possible that in human infection both quantity and sequence of presentation of Shiga toxin and LPS in the tissues determine the development of the pathological events.

NO is a suitable candidate for modulating many of the pathological manifestations attributed to Shiga and Shiga-like toxins. As a modulator of inflammation, NO plays a role in the formation of oedema and, because of its cytotoxicity, also in tissue damage [18]. Thus, NO may be involved in the damage to vascular endothelium described in the intestine as well as in the kidney and brain in shigella infection [4]. Furthermore, as a neurotransmitter of non-adrenergic, non-cholinergic nerves, NO regulates various gastrointestinal functions such as vasodilation and smooth muscle relaxation. Finally, NO may be also involved in the neurological complications of shigella infections. NO is produced in the brain by microglia and astrocytes in response to LPS and cytokines. Its overproduction in the brain has been linked to neurotoxicity during ischaemia and to the induction of seizures [18]. In cerebral malaria, which is characterised by coma and seizures, it has been proposed that NO produced in the peripheral system diffuses through the blood-brain barrier, interfering with normal neuronal NO production and function [19]. A similar situation may also exist in some cases of shigella infection. Convulsions in human shigellosis appear very early in the course of disease, sometimes even before the onset of diarrhoea [1]. A recent study demonstrated that Shiga toxin together with LPS enhanced the susceptibility of mice to PTZ-induced seizures as early as $6 \mathrm{~h}$ after their application, long before paralysis and death, which occurred after 24 $72 \mathrm{~h}[12]$. This strongly suggests that Shiga toxin and LPS interfere with neurological processes very early in the course of infection.

The role of NO and other cytokines in the neurological disturbances during shigellosis are now under investigation in the animal model of shigella-related seizures.

This study was supported in part by Grant no. 90-00017 from the USA-Israel Binational Science Foundation (BSF).

\section{References}

1. DuPont HL. Shigella. Infect Dis Clin North Am 1988; 2: 599605.

2. Barrett-Connor E, Connor JD. Extraintestinal manifestations of shigellosis. Am J Gastroenterol 1970; 53: 234-245.

3. Ashkenazi S, Dinari G, Zevulunov A, Nitzan M. Convulsions in childhood shigellosis. Clinical and laboratory features in 153 children. Am J Dis Child 1987; 141: 208-210.

4. O'Brien AD, Holmes RK. Shiga and Shiga-like toxins. Microbiol Rev 1987; 51: 1206-1220.

5. Tesh VL, Samuel JE, Perera LP, Sharefkin JB, O'Brien AD. Evaluation of the role of Shiga and Shiga-like toxins in mediating direct damage to human vascular endothelial cells. $J$ Infect Dis 1991; 164: 344-352. 
6. Louise CB, Obrig TG. Shiga toxin-associated hemolyticuremic syndrome: combined cytotoxic effects of Shiga toxin, interleukin-1 $\beta$, and tumor necrosis factor alpha on human vascular endothelial cells in vitro. Infect Immun 1991; 59: 4173-4179.

7. Tarr PI. Enterocolitis associated with Shiga-like toxin production: an appropriate animal model at last? Gastroenterology 1994; 106: $540-543$.

8. Fontaine A, Arondel J, Sansonetti PJ. Role of Shiga toxin in the pathogenesis of bacillary dysentery, studied using a Toxmutant of Shigella dysenteriae 1 . Infect Immun 1988; 56: 3099-3109.

9. Howard JG. Observations on the intoxication produced in mice and rabbits by the neurotoxin of Shigella shigae. Br J Exp Pathol 1955; 36: 439-446.

10. Keusch GT, Jacewicz M. The pathogenesis of Shigella diarrhea V. relationship of Shigella enterotoxin, neurotoxin, and cytotoxin. J Infect Dis 1975: 131 Suppl: S33-9.

11. Wiley RG, Donohue-Rolfe A, Keusch GT. Axonally transported Shigella cytotoxin is neurotoxic $J$ Neuropathol Exp Neurol 1985; 44: 496-506.

12. Yuhas $Y$, Weizman A, Dinari G, Ashkenazi S. An animal model for the study of neurotoxicity of bacterial products and application of the model to demonstrate that Shiga toxin and lipopolysaccharide cooperate in inducing neurologic disorder. $J$ Infect Dis 1995; 171: 1244-1249.

13. Raqib R, Lindberg AA, Wretlind B, Bardhan PK, Andersson U, Andersson J. Persistence of local cytokine production in shigellosis in acute and convalescent stages. Infect Immun 1995; 63: 289-296.

14. Tesh VL, Ramegowda B, Samuel JE. Purified Shiga-like toxins induce expression of proinflammatory cytokines from murine peritoneal macrophages. Infect Immun 1994; 62: 5085-5094.

15. Barrett TJ, Potter ME, Strockbine NA. Evidence for participation of the macrophage in Shiga-like toxin II-induced lethality in mice. Microb Pathog 1990; 9: 95-103.

16. Harel Y, Silva M, Giroir B, Weinberg A, Cleary TB, Beutler B. $A$ reporter transgene indicates renal-specific induction of tumor necrosis factor (TNF) by Shiga-like toxin. Possible involvement of TNF in hemolytic uremic syndrome. $J$ Clin Invest 1993; 92: 2110-2116.

17. Nathan $C$. Nitric oxide as a secretory product of mammalian cells. FASEB J 1992; 6: 3051-3064.

18. Moncada S, Higgs A. The L-arginine-nitric oxide pathway. $N$ Engl J Med 1993; 329: 2002-2012.

19. Clark IA, Rockett KA, Cowden WB. Possible central role of nitric oxide in conditions clinically similar to cerebral malaria. Lancet 1992; 340: 894-896.

20. Koprowski $\mathrm{H}$, Zheng YM, Heber-Katz $\mathrm{E}$ et al. In vivo expression of inducible nitric oxide synthase in experimentally induced neurologic diseases. Proc Natl Acad Sci USA 1993; 90 : 3024-3027.

21. Campbell IL, Samimi A, Chiang C-S. Expression of inducible nitric oxide synthase: correlation with neuropathology and clinical features in mice with lymphocytic choriomeningitis J Immunol 1994; 153: 3622-3629.

22. Prado D, Cleary TG, Pickering LK et al. The relation between production of cytotoxin and clinical features in shigellosis. $J$ Infect Dis 1986; 154: 149-155.

23. Ding $\mathrm{AH}$, Nathan $\mathrm{CF}$, Stuehr DJ. Release of reactive nitrogen intermediates and reactive oxygen intermediates from mouse peritoneal macrophages. Comparison of activating cytokines and evidence for independent production. J Immunol 1988; 141: 2407-2412.

24. Yuhas Y, Shemer I, Sarov I, Wallach D. Protection of cells from TNF cytotoxicity by tryptophan and indole. Eur Cytokine Network 1990; 1: 35-40.

25. Stout RD, Li Y, Miller AR, Lambe DW. Staphylococcal glycocalyx activates macrophage prostaglandin $\mathrm{E}_{2}$ and interleukin 1 production and modulates tumor necrosis factor alpha and nitric oxide production. Infect Immun 1994; 62: 4160-4166.

26. Tatro JB, Romero LI, Beasley D, Steere AC, Reichlin S Borrelia burgdorferi and Escherichia coli lipopolysaccharides induce nitric oxide and interleukin- 6 production in cultured rat brain cells. J Infect Dis 1994; 169: 1014-1022.

27. Barrett TJ, Potter ME, Wachsmuth IK. Bacterial endotoxin both enhances and inhibits the toxicity of Shiga-like toxin II in rabbits and mice. Infect Immun 1989; 57: 3434-3437. 